\title{
Discriminatory Dissolution Testing for Liquisolid Compacts Containing a Poorly Water-Soluble Drug (Hydrochlorothiazide)
}

\author{
Amjad Khan ${ }^{1 *}$, Zafar Iqbal², Aman Ullah' ${ }^{3}$, Ibrahim Khadra', Mehrin Sherazi ${ }^{3}$, and Noreen Zeb ${ }^{3}$ \\ ${ }^{1}$ Department of Pharmacy, Kohat University of Science and Technology, Kohat, Pakistan \\ ${ }^{2}$ Department of Pharmacy, University of Peshawar, Peshawar, Pakistan \\ ${ }^{3}$ Department of Pharmacy, Abasyn University, Peshawar, Pakistan \\ ${ }^{4}$ Strathclyde Institute of Pharmacy and Biomedical Sciences, Glasgow, UK
}

e-mail:dr.amjad@kust.edu.pk

\begin{abstract}
Drug release from liquisolid compacts is dependent on several variables and changes in experimental parameters, like drug loading and the type and quantity of the carrier material, which affect the dissolution rate, significantly. Therefore, a dissolution method is needed that can discriminate among in vitro release profiles of liquisolid compacts of varying nature. The objective of this study was to develop and validate a discriminatory dissolution testing method for liquisolid compacts of hydrochlorothiazide (HCTZ) to evaluate the effect of formulation and process variables on dissolution rate. Various experimental conditions were optimized, and the method was validated according to USP and ICH guidelines for different parameters like linearity, specificity, accuracy, precision, and stability of solution. Analysis of dissolution samples was carried out by high-performance liquid chromatography (HPLC). The discriminatory nature of the method was confirmed by determining dissolution rates of liquisolid compacts of HCTZ prepared with different load factors. A model-independent approach was applied for comparison of different dissolution profiles. Based on a screening study, USP apparatus I (basket method) was selected. The best in vitro dissolution profile was obtained using purified water containing Tween-80 $(0.5 \% \mathrm{v} / \mathrm{v})$ as the dissolution medium $(900 \mathrm{~mL})$, stirred at $75 \mathrm{rpm}$. Complete dissolution $(99.83 \pm$ 1.03\%) was achieved within 60 min and dissolution media had no interference with sample analysis. HCTZ exhibited a linear response $\left(r^{2}=0.9974\right)$ in the selected dissolution medium and showed accurate results $(98 \%-100 \%)$ in the concentration rage of $80 \%-120 \%$ of the dose. All validation parameters were found in acceptable range (\%RSD $>2$ ), and drug samples prepared in dissolution medium were stable for the specified period. Comparison of dissolution profiles in the official and developed media showed significant differences in $f_{1}$ and $f_{2}$ values. The developed dissolution test exhibited higher discriminative capacity in differentiating release profiles of HCTZ and can be applied during formulation development and quality control analysis of liquisolid compacts.
\end{abstract}

KEYWORDS: Discriminatory dissolution testing, hydrochlorothiazide (HCTZ), liquisolid compacts

\section{INTRODUCTION}

nternational Conference on Harmonization (ICH) defines "quality by design" as "a systematic approach to the product development that begins with predefined objectives and emphasizes on product and process understanding and control, based on sound science and quality risk management" (1). The quality of pharmaceutical products is evaluated during the lifecycle of the drug allowing the investigation of critical process parameters, having an impact on critical quality attributes. The entire pharmaceutical product development strategy is based upon the Target Product
Quality Profile (TPQP), determining the design and extent of product development $(2,3)$.

Physicochemical properties of drugs are decisive for choosing the excipients in the formulation development phase (4). In vitro dissolution data can be helpful in the evaluation and interpretation of possible risks (5), especially in the case of immediate release and modified release dosage forms on the dose dump and food effects that could influence gastrointestinal conditions (6). A satisfactory in vitro dissolution rate is helpful in predicting the pharmacokinetic properties, which impact the study

*Corresponding author 
design for characterization of pharmaceutical products $(7,8)$. The dissolution rate is dependent on several formulation and process variables, and minor changes will result in large variation, especially with drugs with poor water solubility.

In a quality-by-design approach, the dissolution rates of finished pharmaceutical products are evaluated in sink conditions to test the release of the entire dose. Products are discarded if they do not meet the acceptance criteria for approval (9). Official dissolution testing methods analyze various dissolution media and experimental parameters to determine sink conditions. Some of these methods are unable to discriminate among the products of different quality attributes (prepared with different formulations and under-varied processing parameters). There is always a need for a dissolution testing method that can determine the effect of different variables on dissolution rate. The discriminatory power of the dissolution testing method is its ability to detect the effect of minor changes in process and/or formulation on dissolution rate (10). Demonstration of discriminatory power of a dissolution method is challenging and important, particularly in monitoring active pharmaceutical ingredient (API) or formulation parameters, which are critical for optimal product performance.

The liquisolid technique is a novel approach and has been extensively applied for enhancement of dissolution rates of poorly soluble drugs. A "liquisolid system" refers to formulations formed by conversion of liquid medication to a free-flowing and compressible powder (11). The liquid medication may be a liquid drug, drug solution, or dispersion in water-miscible nonvolatile solvent or solvent system (12). Liquisolid compacts are usually obtained by mixing the liquid medication (liquid drug or drug solution/dispersion) with the carrier material and blending with coating material (13). A powdered solution is formed on the surface of the carrier material, resulting in an enhanced dissolution rate. Liquisolid technology was introduced in 1990s, and Spireas and Sadu were pioneers (14). Since then, extensive research has been made to improve dissolution rates of several poorly soluble drugs by liquisolid technique. It is industrially applicable due to simplicity and cost effectiveness and has no stability issues (14-16). Recently the technique has been applied for preparation of sustained release products using hydrophobic carriers such as Eudragit RL or RS $(17,18)$. As in liquisolid compact, the drug is incorporated as solution or dispersion, and small changes in experimental parameters like drug loading and type and quantity of the carrier material can cause significant changes in the drug release profile. The systematic development of a dissolution method of discriminatory nature is required at the earlier stages of product development, as it enables the formulator to adopt the right approach in finalizing the prototype formula and process for further scale-up (19).

In the present study, hydrochlorothiazide (HCTZ) was selected as a model drug due its poor solubility (20). Its molecular weight is $297.74 \mathrm{~g} / \mathrm{mol}$. According to the Biopharmaceutical Classification System (BCS), HCTZ is a class IV drug and has pKa value of 7.9. It is a diuretic drug and is commonly used as an antihypertensive agent, alone or in combination with the other drugs (21). The USP recommends $900 \mathrm{~mL}$ of $0.1 \mathrm{~N} \mathrm{HCl}$ as dissolution medium for HCTZ, held at $37 \pm 2{ }^{\circ} \mathrm{C}$ and agitated at $100 \mathrm{rpm}$ using USP apparatus I (basket method). The official dissolution test for HCTZ tablets is not suitable for discriminating the dissolution profile or supporting product development process of liquisolid compact dosage forms. Hence, the objective of the study was to develop and validate a discriminatory dissolution testing method for liquisolid compact dosage forms of HCTZ. In the present study, a discriminatory dissolution testing method was developed for liquisolid compacts dosage forms of HCTZ. The developed method was validated in accordance with $\mathrm{ICH}$ and USP guidelines $(22,23)$.

\section{MATERIALS AND METHODS}

\section{Materials}

Model drug HCTZ (purity $99.52 \%$ with respect to the USP reference standard), was provided by Ferozsons Laboratories Pvt. Ltd., Nowshera, Pakistan. All other reagents (acetonitrile, sodium biphosphate, hydrochloric acid and Tween-80) were purchased from pharmaceutical market of Peshawar, Pakistan. All the reagents were of analytical grade and used as received.

\section{Instrumentation}

Dissolution studies were performed in a Pharma Test dissolution testing apparatus (Pharma Test, Germany) while the drug content was determined by high-performance liquid chromatography (HPLC) system (Perkin Elmer, USA). Purified water was prepared by Milli-Q system (Millipore, Milford, MA, USA).

\section{Determination of Equilibrium Solubility of Hydrochlorothiazide (HCTZ)}

Flask shake method was applied for determination of equilibrium solubility of HCTZ in various solvents, as listed below (23). Access of drug was added to the test solvent $(50 \mathrm{~mL})$, sonicated for $10 \mathrm{~min}$ and subjected to continuous shaking through a mechanical flask shaker (Morgan

Dissolution

FEBRUARY 2019 Technologies www.dissolutiontech.com 
Instruments, Pakistan) for $8 \mathrm{~h}$ at ambient temperature. After completion of the shaking period, the solution was kept undisturbed for $1 \mathrm{~h}$ to achieve the equilibrium, filtered (Whatman filter paper \#42; pore size = $2.5 \mu \mathrm{m}$ ) and analyzed for drug content using HPLC.

Equilibrium solubility of HCTZ was determined in:

$$
\begin{aligned}
& \text { 1. Purified water } \\
& \text { 2. Purified water + Tween-80 (0.5\% v/v) } \\
& \text { 3. } 0.1 \mathrm{~N} \mathrm{HCl} \text { (official dissolution media) } \\
& \text { 4. } 0.1 \mathrm{~N} \mathrm{HCl}+\text { Tween- } 80(0.25 \% \mathrm{v} / \mathrm{v}) \\
& \text { 5. Phosphate buffer } \\
& \text { 6. Phosphate buffer + Tween-80 }
\end{aligned}
$$

In each solution, drug content was determined in triplicate and results were presented as mean \pm standard deviation (SD). Composition of phosphate buffer was according to USP and had $\mathrm{pH} 6.8$.

\section{Optimization of Dissolution Testing Conditions}

Liquisolid compact dosage forms containing HCTZ (12.5 $\mathrm{mg}$ ) were prepared in our previous study (13) using combination of polyethylene glycol (PEG-400), purified water, and Tween-60 as a nonvolatile solvent system. Microcrystalline cellulose and colloidal silicon dioxide were used as carrier and coating material, respectively. Liquisolid compact dosage forms were compressed using round, shallow concave punches $(13.5 \mathrm{~mm})$ at a compression weight of $500 \mathrm{mg}$. Tablets from optimal formulation (formulation with highest dissolution rate) were used throughout the study. The officially recommended dissolution medium for HCTZ is $0.1 \mathrm{~N}$ $\mathrm{HCl}(900 \mathrm{~mL})$ held at $37 \pm 2{ }^{\circ} \mathrm{C}$ and agitated at $100 \mathrm{rpm}$, using USP apparatus I (basket method) (23). In the present study, experimental parameters (composition of dissolution medium, type of USP dissolution apparatus, and stirring rate) were studied to produce discriminating results. Composition of the various dissolution media tested were as follows:

$$
\begin{aligned}
& \text { 1. Purified water } \\
& \text { 2. Purified water + Tween-80 }(0.5 \% \mathrm{v} / \mathrm{v}) \\
& \text { 3. } 0.1 \mathrm{~N} \mathrm{HCl} \\
& \text { 4. } 0.1 \mathrm{~N} \mathrm{HCl}+\text { Tween }-80(0.25 \% \mathrm{v} / \mathrm{v}) \\
& \text { 5. Phosphate buffer }
\end{aligned}
$$

One tablet was put into the vessel of dissolution testing apparatus, containing dissolution medium, at $37 \pm 2{ }^{\circ} \mathrm{C}$. Aliquots $(5 \mathrm{~mL})$ were withdrawn at specified time intervals $(0,510,15,30,45$, and $60 \mathrm{~min})$, filtered, and analyzed for amount of drug release by HPLC, in triplicate $(n=3)$. After each sampling, the volume of the dissolution medium was corrected with the same quantity at the same temperature. The dissolution medium was degassed prior to starting the test.

The effect of USP dissolution apparatus type (apparatus I and II) was evaluated by comparing dissolution rates in developed dissolution medium using both apparatuses. To evaluate the effect of stirring on dissolution rate, speed of the apparatus was studied at 50, 75, and 100 rpm.

\section{Determination of HCTZ Content in Dissolution Samples}

During dissolution studies, samples $(5 \mathrm{~mL})$ were collected at specified time intervals, filtered (Whatman filter paper \#42; pore size: $2.5 \mu \mathrm{m}$ ) and analyzed for drug content using HPLC. The HPLC system was equipped with an auto sampler, vacuum degasser, Peltier column oven, pump, and UV-visible detector (PerkinElmer Series 200 system, USA). The chromatographic data was analyzed on PerkinElmer TotalChrom workstation software (version 6.3.1) linked with the LC-system through network chromatography interface $(\mathrm{NCl}) 900$. The Hypersil BDS C8 column $(250 \times 4.6 \mathrm{~mm}, 5 \mu \mathrm{m})$ was used as stationary phase and was protected by a PerkinElmer precolumn guard cartridge $\mathrm{C} 18(30 \times 4.6 \mathrm{~mm}, 10 \mu \mathrm{m})$. A combination of phosphate buffer and acetonitrile $(9: 1, \mathrm{v} / \mathrm{v})$ was used as the mobile phase, pumped at a flow rate of $1.5 \mathrm{~mL} /$ min at ambient temperature. The $\mathrm{pH}$ of the mobile phase was adjusted to 3 after addition of acetonitrile. Detector wavelength was set at $272 \mathrm{~nm}$. Drug content of the samples was determined based on comparison of the area of sample solution to standard solution with the same concentration. The concentration of the standard solution was based on dose of liquisolid compact dosage forms $(12.50 \mathrm{mg}$ ) and volume of dissolution media (900 $\mathrm{mL})$.

\section{Comparison of Dissolution Profiles by the Model- Independent Method}

The model-independent approach, which is based on similarity factor $\left(f_{2}\right)$ and dissimilarity factor $\left(f_{1}\right)$, was applied for comparison of dissolution profile $(24,25)$. An $f_{2}$ value of 50 or greater ensures sameness or equivalence of the two curves. 


\section{Preparation of Standard Stock Solution of HCTZ}

Stock solution of HCTZ was prepared by dissolving drug in methanol to get a concentration of $1 \mathrm{mg} / \mathrm{mL}$. Working solutions were prepared daily by diluting aliquot from stock solution with dissolution media. Each solution was filtered before analysis.

\section{Validation of the Developed Dissolution Testing Method}

According to the standard guidelines $(22,23)$, the selected dissolution method was validated for various parameters such as linearity, specificity, accuracy, precision, and stability. Linearity of the dissolution method was evaluated from the calibration curves constructed at seven different concentration points of HCTZ solution prepared in dissolution medium in the concentration range of $1-50 \mu \mathrm{g} / \mathrm{mL}$. Specificity of dissolution method was evaluated by examining the effect of dissolution medium on peak characteristics (area, height, retention time, and tailing factor) of HCTZ. The selected dissolution medium was evaluated without drug (blank) and with known amount of drug using HPLC and the results was compared. Percent recovery was used to determine accuracy of the proposed dissolution method. Aliquots of the stock solution of HCTZ were added to dissolution medium $(900 \mathrm{~mL})$ to get the drug concentration in the range of $80-120 \%$ of the nominal dose and stirred at 75 rpm for $15 \mathrm{~min}$. Samples ( $5 \mathrm{~mL}$ ) were withdrawn, analyzed for drug content, and percent recovery was calculated.

Precision of the method was determined in terms of repeatability and intermediate precision. For repeatability, the dissolution test was performed in six vessels of the dissolution testing apparatus simultaneously under the same conditions. Intermediate precision was evaluated based on intraday and interday studies.

\section{Stability Study of Solutions}

Stability of the solutions was determined at three temperatures (low: $5 \pm 3{ }^{\circ} \mathrm{C}$, ambient: $24 \pm 3{ }^{\circ} \mathrm{C}$, and elevated: $40 \pm 3{ }^{\circ} \mathrm{C}$ ) for 7 days. Stock solution of HCTZ was diluted with the selected dissolution medium (combination of purified water and Tween-80) to the specified concentration $(20 \mu \mathrm{g} / \mathrm{mL}$ ). Each solution (stock solution, solution prepared in official dissolution medium, and solution prepared in developed dissolution media) was divided into three portions $(n=3)$ and stored at the specified temperatures for 7 days. After completion of the study period, percent recovery of HCTZ was calculated and results were presented as mean \pm SD; \%RSD.

\section{RESULTS AND DISCUSSION}

HCTZ is a diuretics agent that is available as a tablet dosage form, alone, and in combination with other drugs like losartan and valmisartan. Liquisolid compact dosage forms of HCTZ (12.5 mg) prepared in one of our previous studies (13) were used in the study. For dissolution testing of $\mathrm{HCTZ}$, USP recommends $0.1 \mathrm{~N} \mathrm{HCl}$ as the dissolution medium and USP apparatus I (basket) stirred at $100 \mathrm{rpm}$ (23). The official dissolution testing method is unable to discriminate among different formulations of liquisolid compact dosage forms due to higher solubility. So, the objective of this study was to develop and validate a dissolution method for liquisolid compact dosage forms of HCTZ that can discriminate the dissolution profile of the formulations of varying nature.

\section{Equilibrium Solubility of HCTZ}

Solubility plays a prime role in the dissolution of a drug substance. Correlations between solubility and dissolution rate of different drug substances in various media are well-established. The results of the solubility study and the influence of sink conditions of HCTZ are presented Figure 1. Strength of liquisolid compact dosage forms of HCTZ was $12.5 \mathrm{mg}$ (i.e., each liquisolid compact contained $12.5 \mathrm{mg}$ of $\mathrm{HCTZ}$ ) and the ratio of solubility $\left(\mathrm{C}_{\mathrm{s}}\right)$ to the dose $\left(C_{d}\right)$ was used to predict the sink conditions. A sink condition occurs when the amount of drug that can be dissolved in the dissolution medium is three times greater than the amount of drug to be dissolved (10). A low $C_{s} / C_{d}$ ratio shows the existence of non-sink conditions with a subsequent lower dissolution rate. Based on solubility, sink conditions can be achieved using $0.1 \mathrm{~N} \mathrm{HCl}$ and phosphate buffer as dissolution medium, with and without surfactants. Non-sink conditions were expected using purified water (with and without surfactant) due to a smaller dose solubility ratio $(<3)$.

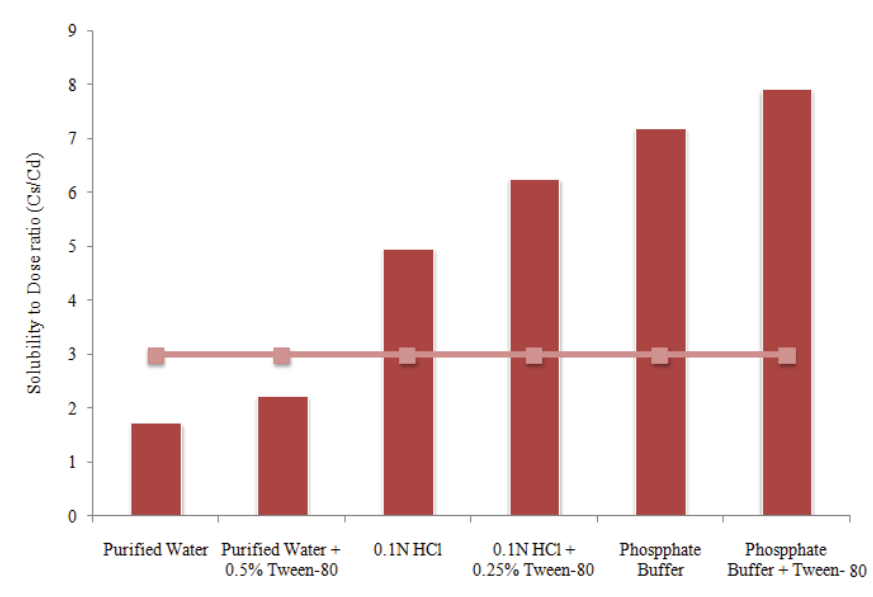

Figure 1. Equilibrium solubility of HCTZ in various dissolution media and correlation with sink conditions. Equilibrium solubility was determined at ambient temperature; horizontal line shows sink condition $\left(C_{s} / C_{d}=3\right)$. $\mathrm{HCl}$, hydrochloric acid; HCTZ, hydrochlorothiazide. 


\section{Selection of Discriminatory Dissolution Test Conditions}

The suitable dissolution test conditions were selected based on the screening study conducted on liquisolid compacts of HCTZ. Dissolution rates were determined in different dissolution media (purified water, purified water + Tween-80, $0.1 \mathrm{~N} \mathrm{HCl}, 0.1 \mathrm{~N} \mathrm{HCl}+$ Tween-80, and phosphate buffer). We evaluated the effect of different USP dissolution testing apparatuses and rotation speed, and the conditions with better discriminatory power were selected.

\section{Selection of Dissolution Medium}

The highest dissolution rate was observed with the officially recommended dissolution medium $(0.1 \mathrm{~N} \mathrm{HCl})$, irrespective of the stirring rate due to sink conditions $\left(C_{s} / C_{d}>3\right)$. Inclusion of Tween-80 further increased its dissolution rate, and most of the drug (71.08 $\pm 0.83 \%)$ released within $15 \mathrm{~min}$, as shown in Figure 2. Except for purified water, abrupt release was observed in all tested dissolution media. HCTZ is practically insoluble in water; incomplete drug release (59.67 $\pm 1.31 \%)$ at a very slow rate was observed using purified water as dissolution medium. Inclusion of Tween-80 into purified water increased the dissolution rate. It was observed that $100 \%$ of drug released from liquisolid compacts within $60 \mathrm{~min}$ in $900 \mathrm{~mL}$ of purified water and Tween-80 (0.5\%, $\mathrm{v} / \mathrm{v})$. Moreover, the dissolution rate was relatively slower and consistent, irrespective of rotation speed of USP apparatus I (basket). Surfactant increased solubility of HCTZ due to its wetting and micelle solubilization action (26). The use of surfactants in the dissolution media for sparingly soluble drugs is physiologically relevant and well-documented (27). A dissolution medium containing surfactant can better simulate the environment of the gastrointestinal tract than a medium containing organic solvents or other nonphysiological substances (28). The addition of a small amount of surfactant below its critical micelle concentration is often sufficient to solubilize certain drug products. In those cases where a higher concentration of surfactant leads to faster dissolution, any potential correlation with in vivo performance is lost (28). Therefore, a low concentration of surfactant is a modifier of choice. In the present study, consistent drug release at a better rate was observed in purified water containing Tween-80 $(0.5 \% \mathrm{v} / \mathrm{v})$, so this was selected as dissolution medium.

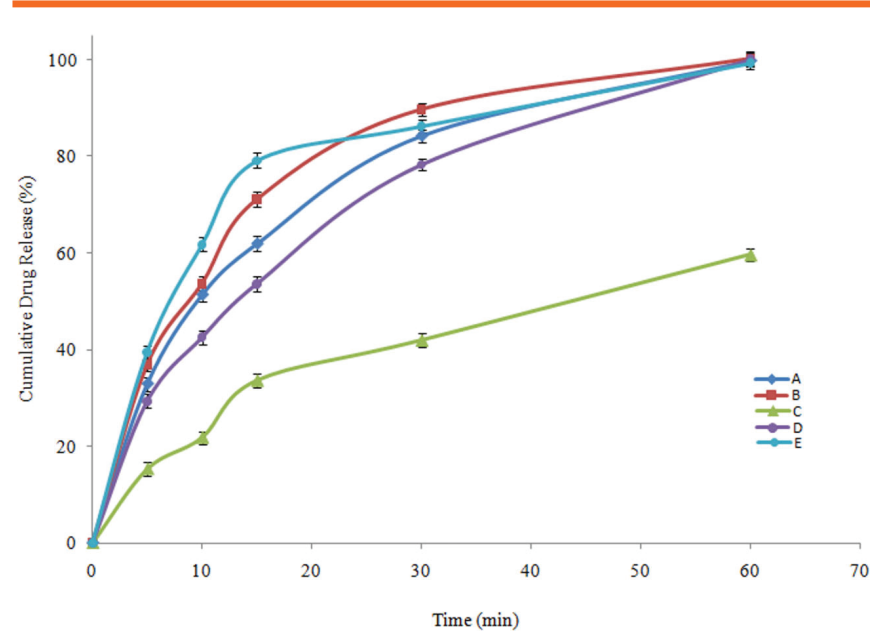

Figure 2. In vitro drug release from liquisolid compacts of HCTZ in $900 \mathrm{~mL}$ of dissolution media of varying nature. $A: 0.1 \mathrm{~N} \mathrm{HCl}$ (official dissolution medium for HCTZ); $B: 0.1 \mathrm{~N} \mathrm{HCl}+$ Tween-80 (0.25\% v/v); C: purified water; D: purified water + Tween-80 (0.5\%, v/v); E: phosphate buffer ( $p H$ 6.8). Dissolution rate was determined using USP apparatus I (basket). At each sampling point, drug content was determined in triplicate, and the mean, $S D$, and SE (error bars) were calculated. $\mathrm{HCl}$, hydrochloric acid, HCTZ, hydrochlorothiazide; SE, standard error.

\section{Type and Speed of USP Dissolution Testing Apparatus}

Different dissolution rates of HCTZ were observed with USP apparatus I (basket) and II (paddle). Dissolution rates were relatively higher with apparatus II, and most of the drug released during the first $15 \mathrm{~min}$. The difference between the two types of apparatuses was insignificant (less than 1\%) in terms of maximum drug release (i.e., the same amount of drug was released at end of the test). Compared with apparatus II, apparatus I resulted in drug release at a slower and consistent rate, as shown in Figure 3, so apparatus I was selected for further study.

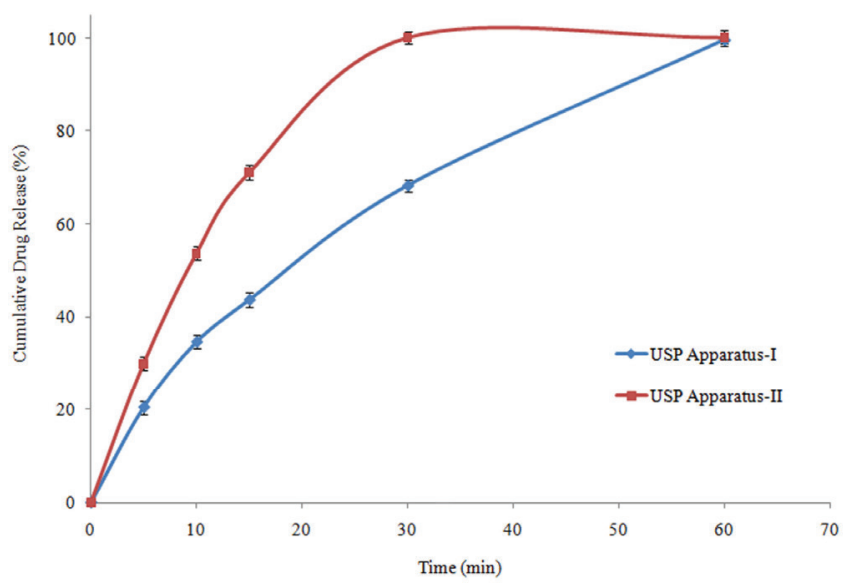

Figure 3. Dissolution rate of HCTZ from liquisolid compacts determined with USP apparatus I (basket) and II (paddle) using the developed dissolution medium (purified water + Tween-80, 0.5\% v/v) at $37 \pm 2{ }^{\circ} \mathrm{C}$. At each sampling point, drug content was determined in triplicate, and the mean, SD (error bars), and SE were calculated. HCTZ hydrochlorothiazide; SE, standard error. 
Liquisolid compacts of HCTZ exhibited different dissolution profiles at different levels of basket speed (50, 75, and $100 \mathrm{rpm})$. The dissolution rate increased with increasing speed of the basket, as shown in Figure 4. At $100 \mathrm{rpm}$, burst drug release was observed within initial 10 min, making it difficult to discriminate among different formulations. On the other hand, incomplete drug release (63.48 $\pm 1.59 \% ; n=3)$ was observed at lowest speed (50 rpm). Consistent drug release at optimum rate was observed at $75 \mathrm{rpm}$, so this was selected as rotation speed of the basket.

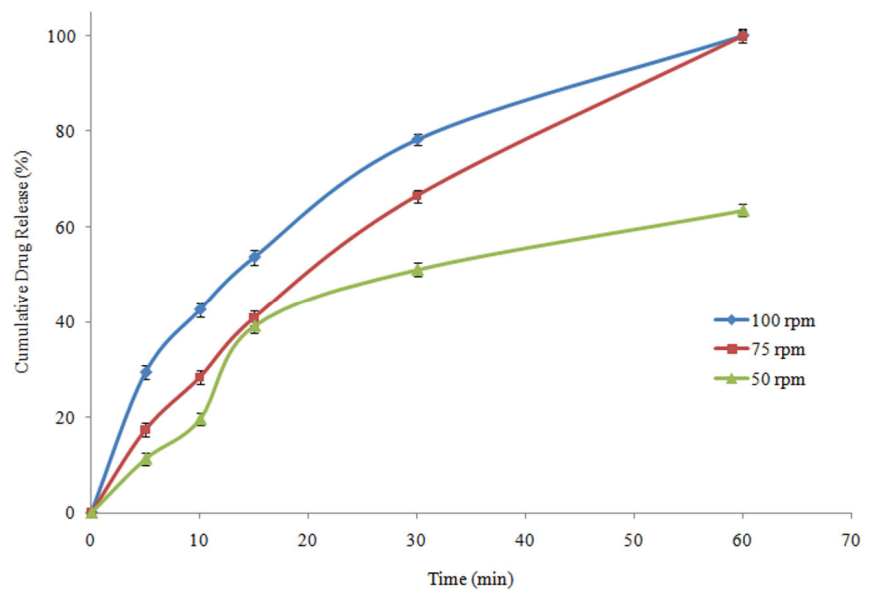

Figure 4. In vitro drug release from liquisolid compacts of HCTZ determined at different speeds (50,75, and $100 \mathrm{rpm})$ using USP apparatus I (basket) in $900 \mathrm{~mL}$ of dissolution medium (purified water $+0.5 \%$ Tween-80), at $37 \pm 2^{\circ} \mathrm{C}$. At each sampling point, drug content was determined in triplicate, and the mean and SD (error bars) were calculated. HCTZ, hydrochlorothiazide.

USP apparatus I, at $75 \mathrm{rpm}$, and $900 \mathrm{~mL}$ of purified water containing $0.5 \%$ Tween- 80 were chosen as conditions for dissolution testing of liquisolid compacts.

\section{Confirmation of Discriminatory Dissolution Test Conditions}

For confirmation of discriminatory dissolution test conditions, liquisolid compacts of HCTZ were prepared at different load factors, and drug release was studied using the selected dissolution medium (purified water + Tween-80) under optimal test conditions $(900 \mathrm{~mL}$ of dissolution medium held at $37 \pm 2{ }^{\circ} \mathrm{C}$ and basket speed of $75 \mathrm{rpm}$ ). Different dissolution profiles were obtained with liquisolid compact of varying nature (i.e., different load factors, 0.25 and 0.50 ), as shown in Figure 5. Drug release from both types of liquisolid compacts was similar in the official dissolution medium, indicating its indiscriminative nature. HCTZ is highly soluble in the official dissolution media and the drug is released quickly, masking the effect of variables (liquid load factor). The liquid load factor is defined as the ratio of the weight of liquid medication to weight of the carrier powder and is calculated by the following equation: $L f=W / Q$, where $L f$ is the liquid load factor, $W$ is the weight of the liquid medication (solvent and drug), and $Q$ is the weight of the carrier powder.
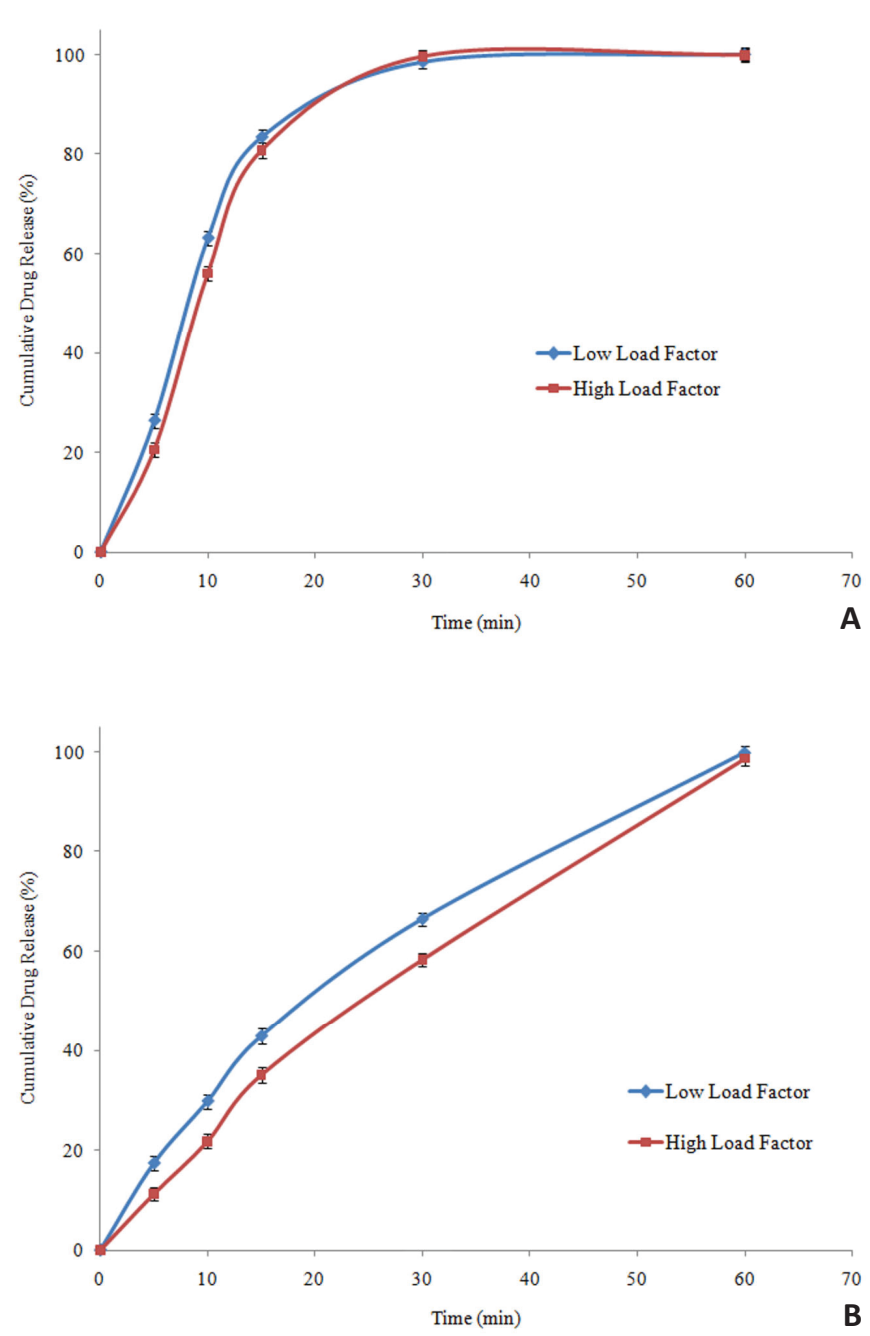

Figure 5. In vitro drug release from liquisolid compacts of HCTZ, with high (0.50) and low (0.25) load factor, determined in official dissolution medium $(0.1 \mathrm{~N} \mathrm{HCl})(\boldsymbol{A})$ and developed dissolution medium (purified water + Tween-80 0.5\%, v/v) (B) at constant volume (900 mL) and basket speed (75 rpm). At each sampling point, drug content was determined in triplicate and the mean and SD (error bars) were calculated. $\mathrm{HCl}$, hydrochloric acid; HCTZ, hydrochlorothiazide.

A higher liquid load factor value indicates more liquid medication in the system and vice versa. Liquid medication consists of nonvolatile solvent system and the API. Liquid load factor is usually increased by increasing nonvolatile solvent, as the amount of API (desired dose) is always constant. By increasing liquid load factor, the amount of the solvent increases and API is diluted, resulting in higher dissolution rate and vice versa. In the present study, using the developed dissolution testing method, different dissolution profiles were obtained. The modelindependent approach, based on $f_{2}$ and $f_{1}$, was applied for comparison of dissolution profiles. Values of similarity

|Dissolution 
factor $\left(f_{2}=39\right)$ and dissimilarity factor $\left(f_{1}=72\right)$ confirmed dissimilarity of the dissolution profiles of liquisolid compact with different load factor values, as determined in the developed and official dissolution medium.

Based on the above results, the dissolution test conditions (purified water + Tween-80, $0.5 \% \mathrm{v} / \mathrm{v}$ ) were considered as discriminative because of differentiation between the products with different pharmaceutical attributes (i.e., variation in liquid load factor).

\section{Validation of the Developed Dissolution Testing Method}

Based on the above results, $900 \mathrm{~mL}$ of purified water containing Tween-80 $(0.5 \%, \mathrm{w} / \mathrm{v})$ with a basket (USP apparatus I) speed of $75 \mathrm{rpm}$ was selected as discriminative dissolution test conditions for liquisolid compacts of HCTZ. The developed dissolution testing method was validated according to the standard (USP and $\mathrm{ICH}$ ) guidelines $(22,23)$.

Regression analysis of calibration curve, constructed at seven concentration levels in the range of $1-50 \mu \mathrm{g} /$ $\mathrm{mL}$, showed that the method is quite linear. Regression equation and correlation coefficient values of calibration curves are presented in Table 1, indicating linearity of the method.

Specificity of the method was estimated based on chromatographic response of the blank dissolution medium and dissolution medium containing different concentrations of HCTZ. Chromatogram of dissolution medium was free of any interfering peaks while different concentrations of HCTZ exhibited peaks with concentration dependent area and constant retention time. Peak purity was confirmed by examining with the peak purity tool, provided in the HPLC software. The obtained value for the peak purity was approximately 1 , indicating high purity.

Accuracy of the method was evaluated based on percent recovery, and values in the range of $95 \%-105 \%$ are considered acceptable. The mean recovery for HCTZ was in the range of $98 \%-100 \%$, as shown in Table 1, indicating high accuracy of the method.

Precision of the method was evaluated based on repeatability using intraday and interday studies; results are summarized in Table 1 . The \%RSD value is less than $1 \%$, indicating good precision of the method.
Table 1. Validation Parameters for Discriminatory Dissolution Testing Method Developed for Liquisolid Compact Dosage Forms of $\operatorname{HCTZ}(n=3)$

\begin{tabular}{|l|c|}
\hline Parameter & Result (Mean \pm SD; \%RSD) \\
\hline Linearity & $1-50 \mu \mathrm{g} / \mathrm{mL}$ \\
\hline Calibration Range & $\mathrm{Y}=0.0269 \mathrm{X}$ \\
\hline Regression Equation & 0.9974 \\
\hline Correlation Co-efficient $\left(R^{2}\right)$ & \\
\hline Accuracy & $99.09 \pm 0.73 ; 0.74$ \\
\hline $10 \mathrm{mg}(80 \%)$ & $99.63 \pm 0.41 ; 0.41$ \\
\hline $12.5 \mathrm{mg}(100 \%)$ & $98.57 \pm 0.67 ; 0.68$ \\
\hline 15 mg $(120 \%)$ & \\
\hline Precision & \\
\hline Repeatability & $100.10 \pm 0.67 ; 0.67$ \\
\hline Vessel-1 $\left(\mathrm{V}_{1}\right)$ & $99.63 \pm 0.41 ; 0.41$ \\
\hline Vessel-2 $\left(\mathrm{V}_{2}\right)$ & $99.80 \pm 0.93 ; 0.93$ \\
\hline Vessel-3 $\left(\mathrm{V}_{3}\right)$ & $99.51 \pm 0.63 ; 0.63$ \\
\hline Vessel-4 $\left(\mathrm{V}_{4}\right)$ & $99.79 \pm 0.86 ; 0.86$ \\
\hline Vessel-5 $\left(\mathrm{V}_{5}\right)$ & $100.53 \pm 0.69 ; 0.69$ \\
\hline Vessel-6 $\left(\mathrm{V}_{6}\right)$ & \\
\hline Intraday Reproducibility & $100.10 \pm 0.67 ; 0.67$ \\
\hline $8 \mathrm{~h}$ & $99.30 \pm 0.29 ; 0.29$ \\
\hline $16 \mathrm{~h}$ & $99.48 \pm 0.53 ; 0.53$ \\
\hline $24 \mathrm{~h}$ & $98.92 \pm 0.33 ; 0.33$ \\
\hline Interday Reproducibility & $99.60 \pm 0.81 ; 0.81$ \\
\hline Day 1 & \\
\hline Day 2 & \\
\hline Day 3 & \\
\hline & \\
\hline
\end{tabular}

Dissolution medium: $900 \mathrm{~mL}$ purified water + Tween-80 (0.5\%) at $37 \pm$ $2{ }^{\circ} \mathrm{C}$; basket speed: $75 \mathrm{rpm}$. $\mathrm{HCTZ}$, hydrochlorothiazide; RSD, relative standard deviation.

\section{Stability of Solution}

Stability of the HCTZ solution prepared in dissolution medium was evaluated at three different temperatures and compared with the solution prepared in methanol and in the official dissolution medium. The drug content of the samples was within $99 \%-100 \%$ (Table 2 ) of the initial value over the test period ( 7 days), and no degradation products were observed in any of the chromatograms, indicating stability of HCTZ in dissolution medium. 
Table 2. Percent Recovery (Stability) of HCTZ from Stock Solution (Prepared in Methanol) and Solution Prepared in Dissolution Medium After Storage at Different Conditions for 7 Days $(n=3)$.

\begin{tabular}{|l|c|c|c|}
\hline \multirow{2}{*}{$\begin{array}{l}\text { Composition of } \\
\text { Solvent }\end{array}$} & \multicolumn{3}{|c|}{ Percent Recovery (Mean \pm SD) } \\
\cline { 2 - 4 } & $\begin{array}{c}\text { Ambient } \\
\text { Temperature } \\
\left(24 \pm 3^{\circ} \mathrm{C}\right)\end{array}$ & $\begin{array}{c}\text { Lower } \\
\text { Temperature } \\
\left(5 \pm 3^{\circ} \mathrm{C}\right)\end{array}$ & $\begin{array}{c}\text { Elevated } \\
\text { Temperature } \\
\left(40 \pm 3^{\circ} \mathrm{C}\right)\end{array}$ \\
\hline Stock solution & $99.31 \pm 0.69$ & $99.46 \pm 0.78$ & $99.38 \pm 0.63$ \\
\hline $\begin{array}{l}\text { Developed dissolution } \\
\text { medium }\end{array}$ & $99.89 \pm 0.72$ & $99.93 \pm 0.59$ & $99.21 \pm 0.81$ \\
\hline $\begin{array}{l}\text { Official dissolution } \\
\text { medium }\end{array}$ & $99.04 \pm 0.60$ & $99.90 \pm 0.67$ & $99.34 \pm 0.95$ \\
\hline
\end{tabular}

HCTZ, hydrochlorothiazide.

\section{CONCLUSION}

A robust, discriminating dissolution testing method was developed for liquisolid compacts of HCTZ and validated according to the standard guidelines (USP and ICH). An initial study was conducted by evaluating the dissolution profiles of liquisolid compacts in different dissolution media using USP apparatus I and II at different speeds $(50,75$, and $100 \mathrm{rpm})$. The use of $900 \mathrm{~mL}$ of purified water containing Tween-80 $(0.5 \% \mathrm{v} / \mathrm{v})$ as the dissolution medium, at $37 \pm$ $0.5{ }^{\circ} \mathrm{C}$, and apparatus I at $75 \mathrm{rpm}$ produced satisfactory results. Dissolution profiles of liquisolid compacts, having different load factors resulted in different dissolution profiles, confirming the discriminatory nature of the method. Comparison of the obtained dissolution profiles using similarity and dissimilarity factors showed significant differences. The developed dissolution method will be helpful in formulation development of liquisolid compacts and assessment of quality and performance of different batches.

\section{ACKNOWLEDGEMENT}

We are thankful to the management of the Ferozsons Laboratories Pvt. Ltd. Nowshera, Pakistan, for provision of $\mathrm{HCTZ}$ reference standard.

\section{CONFLICT OF INTEREST}

The authors disclosed no conflicts of interest related to this article.

\section{REFERENCES}

1. Dagro, S. The International Conference on Harmonization of Technical Requirements for Registration of Pharmaceuticals for Human Use (ICH). In Handbuch Ethik und Recht der Forschung am Menschen; Lenk C., Duttge G., Fangerau H., Eds. Springer: Heidelberg. 2014. DOI: 10.1007/978-3-642-35099-3_86.

2. Ali, J.; Pramod, K.; Tahir, M. A.; Charoo, N. A.; Ansari, S. H. Pharmaceutical product development: $A$ quality by design approach. Int. J. Pharm. Investig. 2016, 6, 129. DOI: 10.4103/2230973x.187350.

3. Sangshetti, J. N.; Deshpande, M.; Zaheer, Z.; Shinde, D. B.; Arote, R. Quality by design approach: regulatory need. Arab. J. Chem. 2017, 10, 3412-3425. DOI: 10.1016/j.arabjc.2014.01.025.

4. Yu, L. X.; Amidon, G.; Khan, M. A.; Hoag, S. W.; Polli, J.; Raju, G. K.; Woodcock, J. Understanding pharmaceutical quality by design. AAPS J. 2014, 16, 771-783. DOI: 10.1208/s12248-014-9598-3.

5. Gabriel, S. E.; Jaakkimainen, L.; Bombardier, C. Risk for serious gastrointestinal complications related to use of nonsteroidal anti-inflammatory drugs: a meta-analysis. Ann. Intern. Med. 1991, 115, 787-796. DOI: 10.7326/0003-4819-115-10-787.

6. Qureshi, S. A. Developing discriminatory drug dissolution tests and profiles: Some thoughts for consideration on the concept and its interpretation. Dissolut. Technol. 2006, 13, 18-23. DOI: 10.14227/dt130406p18.

7. Siewert, M. Perspectives of in vitro dissolution tests in establishing in vivo/in vitro correlations. Eur. J. Drug Metab. Pharmacokinet. 1993, 18, 7-18. DOI: 10.1007/bf03220004.

8. Hubert, C.; Lebrun, P.; Houari, S.; Ziemons, E.; Rozet, E.; Hubert, $\mathrm{P}$. Improvement of a stability indicating method by quality-bydesign versus quality-by-testing: A case of a learning process. J. Pharm. Biomed. Anal. 2014, 88, 401-409. DOI: 10.1016/j. jpba.2013.09.026.

9. Yu, L. X. Pharmaceutical quality by design: product and process development, understanding, and control. Pharm. Res. 2008, 25, 781-791. DOI: 10.1007/s11095-007-9511-1.

10. Khan, A. Development and validation of discriminatory dissolution testing method for orally disintegrating tablets of domperidone. Dissolut. Technol. 2017, 24, 28-36. DOI: 10.14227/ DT240217P28.

11. Nokhodchi, A.; Hentzschel, C. M.; Leopord, C. S. Drug release from liquisolid system: speed it up, slow it down. Expert Opin. Drug Del. 2011, 8, 191-205. DOI: 10.1517/17425247.2011.548801.

12. Fahmy, R. H.; Kaseem, M. A. Enhancement of famotidine dissolution rate through liquisolid tablet formulation: In vitro-in vivo evaluation. Eur. J. Pharm. Biopharm. 2008, 69, 993-1003. DOI:10.1016/j.ejpb.2008.02.017.

13. Khan, A.; Iqbal, Z.; Shah, Y.; Ahmad, L.; Ismail; Ullah, Z.; Ullah, A. Enhancement of dissolution rate of class II drugs (hydrochlorothiazide); a comparative study of the two novel approaches; solid dispersion and liqui-solid techniques. Saudi Pharm. J. 2015, 23, 650-657. DOI: 10.1016/j.jsps.2015.01.025.

14. Fahim, J. S.; Sachin, L. T.; Umesh, B. K. Design and development of liquisolid compact of candesartan cilexetil to enhance dissolution. J. Pharm. Res. 2013, 7, 381-388. DOI: 10.1016/j. jopr.2013.05.012.

15. Spireas, S.; Sadu, S. Enhancement of prednisolone dissolution property using liquisolid Compacts. Int. J. Pharm. 1998, 166, 177-188. DOI: 10.1016/s0378-5173(98)00046-5.

16. Yousef, J.; Jafari, B.; Nokhodchi, A. Liquisolid technique for disolution rate enhancement of a high dose water insoluble 
carbamazepine. Int. J. Pharm. 2007, 341, 26-34. DOI: 10.1016/j. ijpharm.2007.03.034.

17. Tiong, N.; Elkordy, A. A. Effect of liquisolid formulations on dissolution of naproxen. Eur. J. Pharm. Biopharm. 2009, 73, 373-384. DOI: 10.1016/j.ejpb.2009.08.002.

18. Enugula, P.; Sheik, N.; Izhar, A. S. Liquisolid technique based sustained release tablet of trimetazidine dihydrochloride, Drug Invent. Today. 2013, 5, 302-310. DOI: 10.1016/j.dit.2013.08.006.

19. Singla, N.; Gupta, G. D.; Kohli, K.; Singla, A. K. A discriminatory and biorelevant dissolution test method for simvastatin drug products. Dissolut. Technol. 2009, 16, 11-13, DOI: 10.14227/ DT160409P11.

20. Sanphui, P.; Rajput, L. Tuning solubility and stability of hydrochlorothiazide co-crystals, Acta Cryst. 2014, B70, 81-90. DOI: 10.1107/s2052520613026917.

21. Asma, H. Solid dispersion to improve dissolution of drug product, Int. J. Pharm. Life Sci. 2013, 2, 42-58. DOI: 10.3329/ ijpls.v2i1.15134.

22. Note for guidance on validation of analytical procedures; CPMP/ ICH/381/95; Committee for Medicinal Products for Human Use (CHMP), European Medicine Agency, London, 1995.

23. The United States Pharmacopeia and National Formulary USP 35-NF 30; The United States Pharmacopeial Convention, Inc.: Rockville, MD, 2015.
24. Paulo, C.; Jose, M. S. L.; Modeling and comparison of dissolution profiles. Eur. J. Pharm. Sci. 2001, 13, 123-133. DOI: 10.1016/ S0928-0987(01)00095-1.

25. Pseidy, L. M.; Roberto, R.; María, D. V. Matrix tablets: The effect of hydroxypropyl methylcellulose/anhydrous dibasic calcium phosphate ratio on the release rate of a water-soluble drug through the gastrointestinal tract I. In vitro tests. AAPS PharmSciTech. 2012, 13, 1073-1083. DOI: 10.1208/s12249-0129829-9.

26. Vladimir, P. T. Structure and design of polymeric surfactantbased drug delivery systems, J. Control. Rel. 2001, 73, 137-172. DOI: 10.1016/S01683659(01)00299-1.

27. Cynthia, K. B.; Hitesh, P. C.; Beverly, N.; Robert, A. R.; Brian, R. R.; Pankaj, A. S. Acceptable analytical practices for dissolution testing of poorly soluble compounds. Dissolut. Technol. 2005, 12, 6-12. DOI: 10.14227/dt120405p6.

28. Rodrigo, C.; Jennifer, B. D. Dissolution methods to increasing discriminatory power of in vitro dissolution testing for ibuprofen free acid and its salts. J. Pharm. Sci. 2016, 106, 1-8. DOI: 10.1016/j.xphs.2016.06.001. 